\title{
Improving the Durability of Cement-based Grouts against Adverse Climatic Conditions in Cold Climates
}

\author{
${ }^{1}$ Amin Gholizad, ${ }^{2}$ Meysam Shirzad Shahrivar* \\ ${ }^{1}$ Associate Professor, Mohaghegh Ardabili University, Ardabil, Iran \\ email: meysam.shirzad.1992@gmail.com \\ ${ }^{2}$ MSc. in Structural Engineering, University of Mohaghegh Ardabili, Ardabil, Iran
}

\begin{abstract}
Cement-based grouts (CBGs) are of the materials that receive significant attention nowadays given their widespread application in the structure industry. Grouts' performance must be such that well perform the task of absorbing and transmitting various static and dynamic loads to mostly concrete substrates and foundations and be resistant against the issues and risks that threaten grouts health, durability, and quality during their service life. Continuous freeze and thaw damage of water inside the grout are of the common causes of vulnerability in cold climates. The study tried to prevent the creation of these cracks by presenting new mix designs and modifying grouts structure using modern materials and technologies of nano and micro materials. The mix designs designed and tested in this paper were based on the replacement of the weight percentage of cement with microsilica and nanosilica and the comparison of changes and their effects on various properties of the grout. The results obtained from the study showed the significant and positive effect of weighted replacement of the controlled amount of microsilica and nanosilica instead of cement in terms of durability and grout resistance under adverse climatic conditions in cold areas. According to the results, the modification of the mix design with this method significantly prevented the compressive strength loss and reduced the negative effect of continuous thaw and freeze cycles to $7 \%$ in some cases.
\end{abstract}

Keywords: Grout, durability, thawing and freezing test, nanosilica, microsilica

\section{Introduction}

In the present age, the significance of speed, accuracy, and strength of installation and replacement of huge structural elements and industrial machinery and tools at the project site using different types of grouts becomes more clear than ever given the progress in the construction industry, the ever-increasing development of precise and quick construction, and the mechanization of production, assembly and installation processes of industrial machinery and structural elements. Given the significance of grout uses in the building industry and its functions in absorbing and transmitting various static and dynamic loads to mostly concrete substrates and foundations and be resistant against the issues and risks that threaten grouts health, durability, and quality during their service life, producing grouts with specific specialties that are durable and well perform the task of adhesion and filling the wall plates, do not reduce volume after grouting, can withstand load transfer to the foundation, and do not lose strength under adverse weather conditions and thaw and freeze cycles ruling the cold regions seem essential [1].

\section{Pathology and the necessity of the study}

The damage caused by continuous thaw and freeze of water inside the grout is one of the common causes of vulnerability in cold climates. The following conditions are effective in the occurrence of freeze and thaw damage:

1- When the structure is constantly affected by thaw and freeze cycle, and 2- when the pores in the grout are saturated with water (over 90\%) during the freeze

Water undergoes about $15 \%$ volumetric expansion during freezing. If the pores and capillary cavities in the grout are almost saturated during freezing, the expansion will cause tensile forces that end in fracture and cracking of the cement mortar matrix [2]. This destruction occurs in nearly all layers of grout from the outer surfaces to the inside. The rate of damage progression depends on the number of freeze and thaw cycles, degree of structural saturation during freezing, grout porosity, and light exposure conditions. The grout used in industrial flooring, the grout used in substrate plates used in foundations, walls exposed to snow thaw or spray, horizontal slabs in contact with water, and vertical walls crossing the water path are of the most common state of damage due to continuous freeze and thaw. In cold climates, grouts usually undergo a half cycle of freeze at night and a half cycle of thaw per day within 24 hours [4]. 
Another form of damage caused by freeze and thaw cycle is known as D-cracking (some cracks as capital D letter). In this case, the expansion of damage occurs due to poor quality, high adsorption, and using large aggregates in cement mortars [5]. This type of cracking is usually found in unmarked corners of walls or slabs and joints. In such damage, a series of roughly parallel cracks, of which calcite (lime) leaks out usually and cuts across the corners of the structure.

\section{Literature review and solution presentation}

In 1942, the Bureau of Reclamation formally began using additives in concrete and grout for decreasing the thaw and freeze cycle. The Angostura Dam, whose construction started in 1946, was the first dam built using additives was to stop such cracks.

As already stated, the damage due to freeze and thaw cycle of the grout happens just when the grout is somehow saturated. Thus, the successful damage reduction will involve reducing or eliminating freeze and thaw cycle or reducing in water absorbed by the grout. Usually, there is no known approach for protecting and insulating grouts for temperature control in freeze and thaw cycles, but grout sealing compounds can be used to prevent or reduce water absorption for visible surfaces. Sealing materials for grout immersed in water is not effective, yet it can protect groups exposed to wind, rain, and snow.

The study tried to prevent these cracks by presenting new mix designs and modifying the grout structure using modern materials and nano and micro materials technology.

It has to be noted that regarding cracked concrete structures restoration, the grout produced in this study can be used to fill the cracks and to eliminate constituent failure and integrated performance in it.

\section{Overall description of the activities conducted}

In the paper, various grout samples with different ratios of materials and new materials using micro and nanomaterials were produced for conducting the experiments and investigations. Thus, regarding this, $22 \mathrm{mix}$ designs were designed and the needed samples were produced accordingly and kept to the desired age.

It has to be explained that mix design 1 is the simplest and most common mix design for the grouts used and consists only of water, cement and sand, and designs 2 to 21 are nano- and micromaterial modified designs that besides the above compounds include various modes of grout design with the presence of 2, 1, 0 and $3 \%$ nanosilica and $20,15,10,5,0$ and $25 \%$ microsilica respectively. Finally, the mix design 22 is the representative of the readymade powdered grouts in the market supplied as powder ready to mix and according to the recommendation of the manufacturing company only need to add some water.

It has to be noted that in mix coding, $\mathrm{N}$ represents the percentage of nanosilica replacing the cement and $\mathrm{M}$ the percentage of microsilica. For instance, code GN0M15 means nanosilica-free grout with 15\% microsilica.

Overall, 396 five cubic-centimeter specimens were produced in this study to be tested at 28, 56, and 74 days of age to maintain the desired age.

\section{The method of applying thaw and freeze cycles in the laboratory}

All laboratory specimens were built in two series of 1 and 1l. Moreover, 1-series specimens were examined for freeze-thaw test and 11-series specimens as the ones under proper storage conditions.

According to ASTM C666 Standard, thaw and freeze cycle must be done by one of two approaches below:

Approach A: Rapid thaw and freeze in water

Approach B: Rapid freeze in air and thaw in water

Both of these approaches tend to specify the effect of changing grout properties on the resistance of thaw and freeze cycles by specific methods. Neither of these two approaches tends to measure the length of service expected of grout for a particular type of grout.

In this study, Approach B was selected according to the facilities available. Based on the standard guidelines, the specimens reach $-18^{\circ} \mathrm{C}$ from $4{ }^{\circ} \mathrm{C}$ during freezing and $4{ }^{\circ} \mathrm{C}$ from $-18^{\circ} \mathrm{C}$ during the thaw. In this study, each freeze-thaw cycle took 3 hours, with the specimens placed in freezing conditions for 2 hours and 20 minutes and immersed in water at $20^{\circ} \mathrm{C}$ for 40 minutes. As thaw and freeze cycles were done by humans and given the time limitation of lab working hours, three thaw and freeze cycles were possible per day, so in the non-office hours as recommended by ASTM standard C666 specimens were subjected to freezing.

Specimens of ll-series were placed in a conventional water basin of $20^{\circ} \mathrm{C}$ for treatment before 28,56 , and 74 days of age (along with the cycles of 45, 100, and 150) [4] and during experiments with cyclic specimens were removed from the water under optimum storage conditions and placed in a laboratory environment for 24 hours, after which the appropriate tests were performed on them. 


\subsection{Preliminary results}

\section{Overall results analysis}

After performing all the above stages and specimens reaching age 28, 56, and 74 days and applying the thaw and freeze cycles, 50, 100, and 150 to half of the specimens produced, all 1 and 11 series specimens were tested simultaneously for compressive strength. The results were inserted to the related tables where the results of the specimens under proper storage conditions in the previous sections were analyzed. Now, the compressive strength of the specimens that have undergone various thaw and freeze cycles up to the stated age is examined. The results of this experiment are given in Table 1 and their comparative diagrams are seen in Figure 1.

Moreover, to examine the effect of melt and freeze cycles on each of the specimens produced by presenting specific mix designs, the percentage change in compressive strength of the specimens under inappropriate storage conditions is given in Figure 2. In this chart, each of the specimens with tested mix design code was compared to the specimens maintained under appropriate conditions for the same mix design code at 56, 28 and 74 days of age, equivalent to 50,100 , and 150 cycles.

Table (3-7): The results of compressive strength results of the specimens kept under consecutive thaw and freeze cycles

\begin{tabular}{|c|c|c|c|c|c|c|}
\hline $\begin{array}{c}\text { Mi } \\
\text { design } \\
\text { code }\end{array}$ & $\begin{array}{c}f^{\prime} c \\
28 \text { days } \\
\text { under the } \\
\text { effect } \\
50 \text { cycles }\end{array}$ & $\begin{array}{c}\text { Percentage } \\
\text { of 28-day } \\
\text { strength } \\
\text { loss }\end{array}$ & $\begin{array}{c}f^{\prime} c \\
56 \text { days } \\
\text { under the } \\
\text { effect } \\
100 \text { cycles }\end{array}$ & $\begin{array}{c}\text { Percentage } \\
\text { of 56-day } \\
\text { strength } \\
\text { loss }\end{array}$ & $\begin{array}{c}f^{\prime} c \\
74 \text { days } \\
\text { under the } \\
\text { effect } \\
150 \text { cycles }\end{array}$ & $\begin{array}{c}\text { Percentage } \\
\text { of 74-day } \\
\text { strength } \\
\text { loss }\end{array}$ \\
\hline GNOM0 & 172.13 & $25 \%$ & 159.28 & $34.5 \%$ & 143.12 & $41.75 \%$ \\
\hline GN0M5 & 206.77 & $13.9 \%$ & 205.69 & $19.19 \%$ & 199.33 & $23.21 \%$ \\
\hline GN0M10 & 246.66 & $9.3 \%$ & 251.25 & $12.8 \%$ & 248.31 & $15.5 \%$ \\
\hline GN0M15 & 320.51 & $7.1 \%$ & 329.84 & $9.8 \%$ & 328.79 & $11.86 \%$ \\
\hline GN0M20 & 315.32 & $14.2 \%$ & 313.16 & $19.6 \%$ & 305.63 & $23.7 \%$ \\
\hline GN0M25 & 288.84 & $17 \%$ & 282.28 & $23.47 \%$ & 269.24 & $28.39 \%$ \\
\hline GN1M0 & 295.25 & $10 \%$ & 299.71 & $13.81 \%$ & 297.28 & $16.7 \%$ \\
\hline GN2M0 & 284.12 & $16.3 \%$ & 278.82 & $22.5 \%$ & 267.11 & $27.2 \%$ \\
\hline GN3M0 & 207.36 & $28 \%$ & 187.23 & $38.6 \%$ & 167.57 & $46.76 \%$ \\
\hline GN1M5 & 310.81 & $9 \%$ & 317.04 & $12.4 \%$ & 313.047 & $15.03 \%$ \\
\hline GN1M10 & 458.68 & $6.2 \%$ & 473.96 & $8.5 \%$ & 476.97 & $10.35 \%$ \\
\hline GN1M15 & 515.31 & $5.1 \%$ & 535.04 & $7 \%$ & 542.42 & $8.5 \%$ \\
\hline GN1M20 & 422.04 & $14.74 \%$ & 417.89 & $20.3 \%$ & 400.76 & $24.6 \%$ \\
\hline GN2M5 & 380.76 & $16.5 \%$ & 373.22 & $22.78 \%$ & 356.82 & $27.6 \%$ \\
\hline GN2M10 & 388.68 & $18 \%$ & 377.54 & $24.8 \%$ & 361.47 & $30.06 \%$ \\
\hline GN2M15 & 357.81 & $20.3 \%$ & 342.48 & $28.0 \%$ & 320.52 & $33.9 \%$ \\
\hline GN2M20 & 235.27 & $23 \%$ & 221.01 & $31.7 \%$ & 203.47 & $38.41 \%$ \\
\hline GN3M5 & 280.32 & $27 \%$ & 255.27 & $37.28 \%$ & 226.63 & $45.09 \%$ \\
\hline GN3M10 & 290.75 & $29 \%$ & 260.23 & $40 \%$ & 228.33 & $48.43 \%$ \\
\hline GN3M15 & 225.12 & $33 \%$ & 193.85 & $45.57 \%$ & 165.80 & $55.11 \%$ \\
\hline GN3M20 & 140.64 & $37.3 \%$ & 115.29 & $51.5 \%$ & 91.45 & $62.3 \%$ \\
\hline GJ & 312 & $20 \%$ & 299.22 & $27.62 \%$ & 284.18 & $33.4 \%$ \\
\hline
\end{tabular}




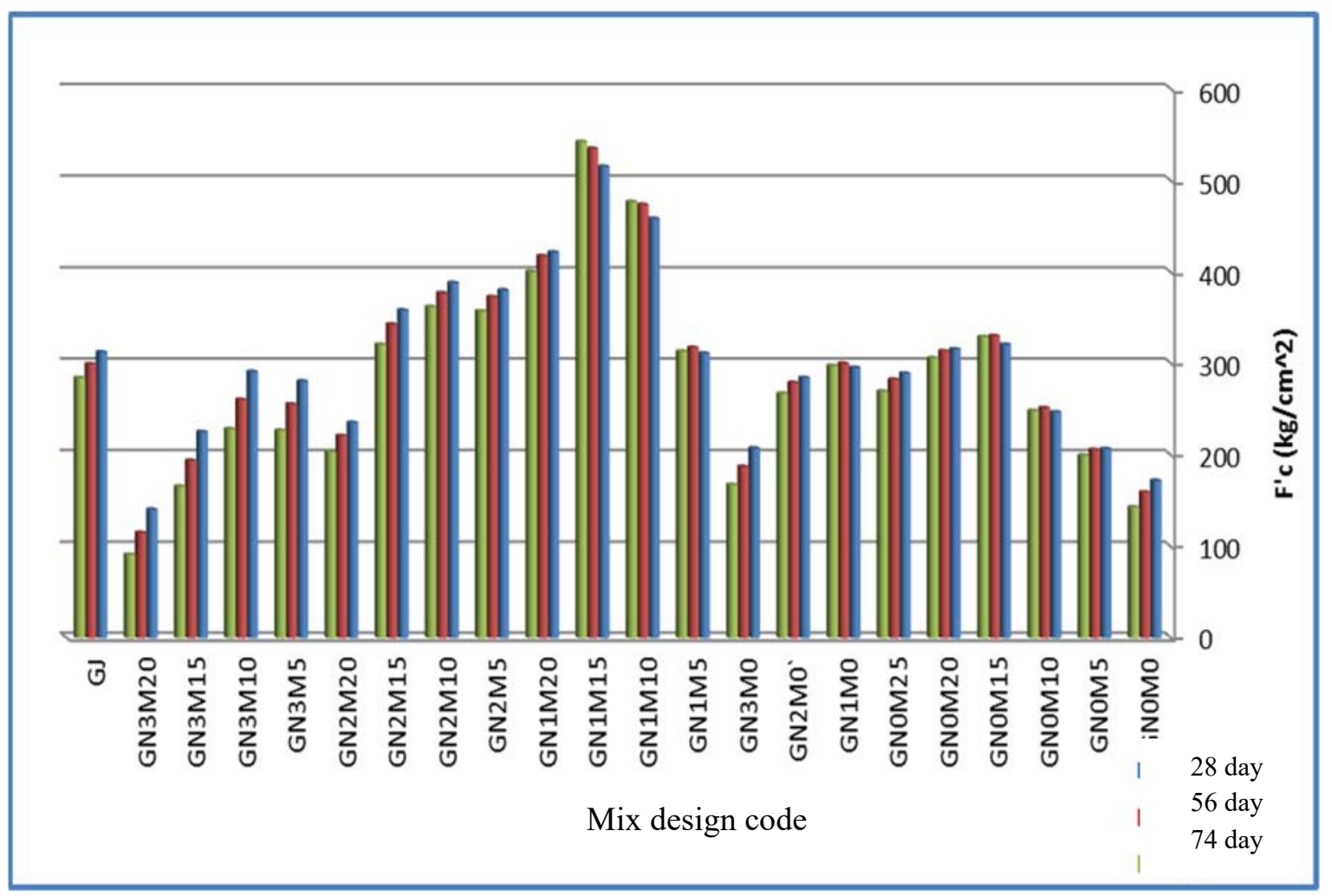

Figure 1: Compressive strength diagram of the specimens stored under consecutive thaw and freeze cycles

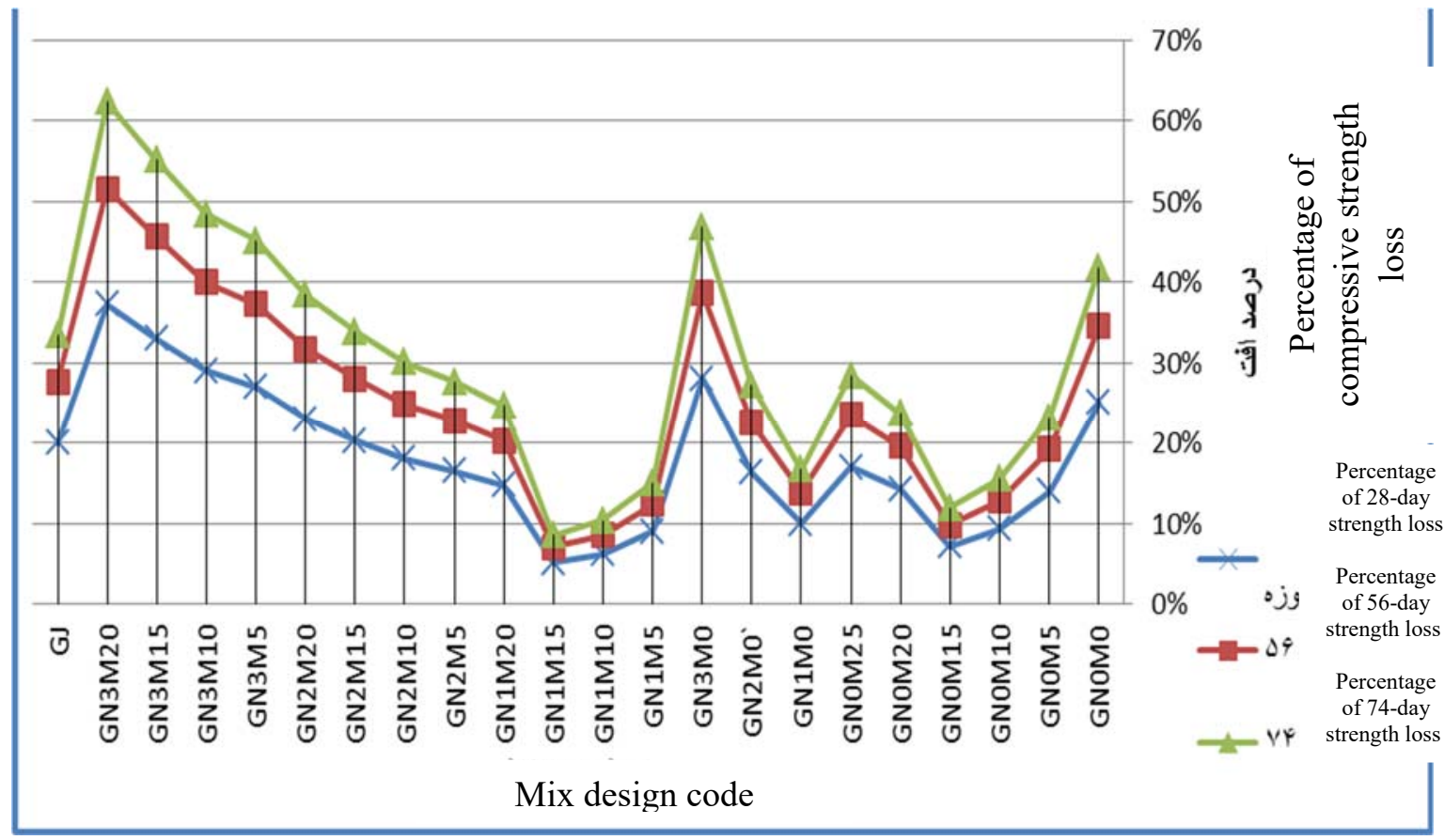

Figure 2: Percentage of specimens' strength loss due to consecutive thaw and freeze cycles

Figure 1 shows the results of the compressive strength test of the specimens stored under adverse conditions: under the effect of 50,100, and 150 consecutive cycles, respectively, for 56, 28 and 74 days.

Generally, the diagram has similarities to the compressive strength diagrams of the specimens in proper storage conditions, but of the major differences is that the compressive strength of the specimens in this section is lower than similar specimens stored under proper conditions, which shows a negative effect of thaw and freeze cycles on grout compressive strength. 
However, the rate of this drop in strength in the specimens varies across the specimens, which calls for more examinations. Moreover, compared to the compressive strength diagrams of the specimens stored at the appropriate conditions at ages of 28,56, and 74 days, we have shown that with an increase in age of the specimens, an increase in the strength, especially at the ages of 28 to 56 days, is evident. However, in Figure 1, most of the specimens showed a decrease in the strength of 74 and 56 days specimens compared to 28 days specimens, which showed the destructive power of continuous 100 and 150 thaw and freeze cycles of the first 50 cycles in the grout.

Then for a detailed and exact study of the effect of adverse atmospheric conditions on the grouts, a figure was presented for comparing the drop in strength due to thaw and freeze cycles on grout and evaluating the effect of nano and micromaterials used on mix designs in Figure 2.

According to these figures, in the first step, $25 \%, 34.5 \%$, and $41.75 \%$ drops are witnessed in the compressive strength of the normal grout (GN0M0) compared to normal storage conditions, which is a very severe drop. Moreover, this drop in the strength of this specimen at 56 and 74 days (equal to 100 and 150 cycles) is significant compared to 28 days ( 50 cycles), which is not a good indication of the future using this grout.

\subsection{Examining the effect of microsilica on grout compressive strength drop because of adverse weather conditions}

Recent explanations on the significant drop in the compressive strength in the grout of the mix design 1 (GN0M0) under successive thaw and freeze cycles are while examining the diagrams of mix designs containing cement replacing microsilica in Figure 2, generally a significant drop is observed in strength. Moreover, no significant differences are seen between the 56 and 74-day charts of each mix design with its 28-day charts in Figure 1, and one can state that replacing microsilica generally leads to relative stability in compressive strength of the specimens under high numbers of consecutive thaw and freeze cycles.

By more precise examinations, it is seen that replacing 5, 10 and $15 \%$ microsilica with cement, respectively, has significantly prevented the drop in the grout compressive strength. Thus, this drop at 56 days of age (equal to 100 cycles) decreased by $19 \%, 12.8 \%$, and $11.8 \%$. However, one has to note that with an increase in silica to 20 and $25 \%$, respectively, a sudden increase is observed in compressive strength drop. Thus, the two mix designs undergo over $20 \%$ strength drop due to 100 thaw and freeze cycles, whose results can be attributed to the sharp drop in the slump of these mix designs while producing the grout specimens that leads to the production of grouts with pores at the surface of the specimen or even inside the grout [8].

\subsection{Examining the effect of nanosilica on grout compressive strength drop because of adverse weather conditions}

In the next step, in the scrutinizing of the diagrams of Figures 1 and 2, we examined the mix designs 7, 8, and 9 mix designs containing 2, 1 and $3 \%$ of cement replacing nanosilica - to reach some conclusions concerning the effect of nanosilica on grout durability under adverse weather conditions.

The results for the compressive strength of the specimens stored in proper conditions showed the positive effect of controlled replacement and a specific amount of nanosilica on the compressive strength of grout. Examination of compressive strength of specimens stored under continuous thaw and freeze cycle diagrams show the positive effect of replacing $1 \%$ by weight of cement with nanosilica in grout composition. Thus, by modifying grout composition, a reduction in the compressive strength of the cubic grout specimens by up to $10 \%$ at 28 days (50 cycles), $13 \%$ at 56 days ( 100 cycles), and $16 \%$ at 74 days ( 150 cycles) is seen. It has to be noted as is seen in Figure (3-16), with an increase in the nanosilica to 2 and $3 \%$ the compressive strength diagram experiences a severe drop. Thus, the GN3M0 mix design affected by 100 and 150 cycles of compressive strength, respectively, showed 38 and $46 \%$ drop compared to proper storage conditions, which will be analyzed fully to find the causes in the next sections in examining the use of nano and micromaterials in grout mixing design.

\subsection{Examining the effect of mixing nanosilica and microsilica on grout compressive strength drop because of adverse weather conditions}

In examining the drop in compressive strength of grout because of thaw and freeze cycles of the specimens with a mixture of nanosilica and microsilica, Figure 2 shows a significant drop in mix designs containing $1 \%$ nanosilica and 5, 10 and $15 \%$ microsilica, respectively. Thus, in the mix designs GN1M5, GN1M10, and GN1M15, the rate of compressive strength drop by 100 consecutive thaw and freeze cycles is reduced to $12,8.5$ and $7 \%$, respectively, where the lowest drop because of multiple thaw and freeze cycles is supposedly related to this part of the graph and specific to GN1M15 mix design.

Then, by increasing the replacement of the stated materials with cement in the grout mix and using 2 and 3\% nanosilica with various compositions of 5,10,15, and $20 \%$ of microsilica, grout compressive strength drop takes a gradual increase and as shown in the diagram increases steadily. This is such that in the mix design containing $3 \%$ nanosilica and microsilica compounds, the rate of strength drop of the specimens because of consecutive cycles of thaw and freeze increases despite the presence of nanosilica and microsilica to the general grout mix design (GM0N0). Moreover, even in GN3M10, GN3M15 and GN3M20 designs, the compressive strength drop 
exceeds that of the mix design in Figure 1 and reaches over 50\%. This means that more than $50 \%$ drop in compressive strength of the grout due to multiple cycles of thaw and freeze is because of the grout storage under proper conditions, whose cause can be examined like the previous cases in the reduction of efficiency and grout slump due to overuse of nanosilica and microsilica. Thus, given the rapid pozzolanic reaction of nanosilica and microsilica relative to cement, a large part of the water used in the grout composition is used for this reaction. Later in the reaction, the excessive pozzolanic materials are not completed and ultimately leads to the production of grout with a low slump that leads to various problems during in vitro molding and in grouting in the workshop place and causes heterogeneity, pores, and cavities on the surface and some cavities within the grout. These points in adverse weather conditions and freezing time turn into a weak point for grout and with water penetration into these cavities and the increase in volume due to the nature of the water molecules because of freezing, it creates stress in the grout and overtime and the repetition of thaw and freeze cycles ends in different damages including severe compressive strength drop and durability of the grout.

\section{Summary}

1. The effect of freeze-thaw cycles as 50,100 , and 150 consecutive cycles on normal grout (GN0M0) with no additives showed $25 \%, 34.5 \%$, and $41.75 \%$, respectively, compressive strength drop compared to normal storage condition that is a sharp drop and not a good sign for the future of using this grout.

2. Replacing microsilica has generally led to a relative stability in compressive strength of the specimens under high numbers of consecutive thaw and freeze cycles, so that with the replacement of 10,5 , and $15 \%$ of microsilica with cement at 56 days of age (equal to 100 cycles), respectively, a drop in the grout compressive strength is observed as $19 \%, 12.8 \%$, and $11.8 \%$, respectively.

3 . With an increase in silica to 20 and $25 \%$, respectively, a sudden increase is observed in compressive strength drop. Thus, the two mix designs undergo over $20 \%$ strength drop due to 100 thaw and freeze cycles, whose results can be attributed to the sharp drop in the slump of these mix designs while producing the grout specimens that leads to the production of grouts with pores at the surface of the specimen or even inside the grout.

4. Replacing an optimized and controlled value of nanosilica with cement in grout compound leads to reduction in the drop of the compressive strength of grout cubic specimens by up to $10 \%$ at 28 days of age (equal to 50 cycles), $13 \%$ at 56 days of age (equal to 100 cycles) and $16 \%$ at 74 days of age (equal to 150 cycles). According to the experiments conducted, this optimum value is replacing nanosilica with a $1 \%$ weight of cement in the mix design.

5. The bottom point of the figure as the percentage of the drop in compressive strength under 100 consecutive cycles of thaw and freeze among 22 mixes designed in the paper related to GN1M15 design, which involves replacing $1 \%$ nanosilica and $15 \%$ microsilica instead of cement. This mix could be considered as the most optimum combination of the study in terms of controlling the compressive strength drop under adverse atmospheric conditions - this mix led to a $7 \%$ decrease in strength drop.

\section{References}

[1] Shirzad Shahrivar, Meysam. (2016). Cement Based Grouts Modified with Micro \& Nano Additives. A thesis submitted in partial fulfillment of the requirements for the degree of M.Sc. in Structural Engineering, University of Mohaghegh Ardabili.

[2] Cyr, M. Lawrence, P. Ringot, E.; "Efficiency of mineral admixtures in mortars: quantification of the physical and chemical effects of fine admixtures in relation with compressive strength", Cem Concr Res 36(2): p.264 -77, 2006.

[3] Ebla, H., Hill, R., "Properties of Concrete Containing Ultra-Fine Fly Ash", ACI Material Journal, No. 100, pp. 426-433, 2003.

[4] ACI 318-83, ACI Committee Report, Building Code Requirements for Reinforced Concrete, American Concrete Institute, 1986.

[5] Neville A.M. and Brooks J.J, "Concrete Technology ", Longman Science \& Technical, 1987.

[6] ACI 302.1R-80, ACI Committee 302 Report, "Guide for concrete floor and slab construction," American Concrete Institute, 1980.

[7] R. Manikandan, K Ramamurthy, "Effect of curing methods on characteristics of cold bonded fly ash aggregates", Cement and Concrete Composites, 30, 2008, 848-85

[8] Pipilikaki, P. Katsioti, M. Gallias, J.L.; "Performance of limestone cement mortars in a high sulfates environment", Construction an Building Materials; (23): p. $1042-1049,2009$.

[9] Amin, Gholizad. Meysam, Shirzad Shahrivar. (2016). Laboratory Evaluation of Dynamic Modulus of Elasticity Cement-Based Grout to Improve the Quality by Using Nano and Micro-Technology. Journal of ASE, pp-13(2)-35-40.

[10] Amin, Gholizad. Meysam, Shirzad Shahrivar. (2016). Numerical investigation of soil and buried structures using finite element analysis. Journal of Structural and Construction Engineering. 3, 4, 1395, 97-104. doi: 10.22065/jsce.2016.41241 